\title{
O TEXTO NA ANÁLISE TEXTUAL DISCURSIVA: UMA LEITURA HERMENÊUTICA DO “TEMPESTADE DE LUZ"
}

\section{THE TEXT IN THE DISCURSIVE TEXTUAL ANALYSIS: A HERMENEUTIC READING OF THE "A LIGHT STORM"}

Robson Simplicio de Sousa ${ }^{1}$

\begin{abstract}
Resumo: Neste texto, apresentamos uma busca pela compreensão do que vem a ser o "texto" na metodologia de análise qualitativa chamada Análise Textual Discursiva (ATD). Trata-se de um exercício com características fenomenológicas e hermenêuticas, ou seja, descrever e interpretar o caráter textual da ATD. Decidimos como corpus de análise um dos textos que marca a tradição dessa metodologia: "Uma tempestade de luz: a compreensão possibilitada pela análise textual discursiva", texto inaugural de ATD. Utilizamos a ATD para analisá-lo e identificar traços do que vem a ser o texto nessa metodologia. Realizamos ainda aproximações com as ideias de Hans-Georg Gadamer e suas contribuições acerca de texto e de interpretação. Alcança-se compreender o texto como um conceito hermenêutico de experiências descritivas e interpretativas a partir do pesquisador como tradutor. Apresenta-se ainda a tarefa promovida pela ATD de aprender sobre um fenômeno enquanto o pesquisador ontologicamente se modifica a partir dos textos do mundo.
\end{abstract}

Palavras-chave: Análise Textual Discursiva; Texto; Hermenêutica.

\begin{abstract}
This paper aims at understanding what "text" means in the qualitative methodology called Discursive Textual Analysis (DTA). It is an exercise with phenomenological and hermeneutical characteristics, i. e., it describes and interprets the textual character of the DTA. The text entitled "A light storm: understanding enabled by the Discursive Textual Analysis", a milestone in the development of the DTA, was chosen to be the corpus of analysis. The DTA is used to analyze it and identify traces of a text that employs this methodology. Approximations with Hans-Georg Gadamer's ideas and his contributions to text and interpretation are also introduced. A text is understood as a hermeneutic concept of researchers' descriptive and interpretive experiences as translators. The paper also shows the task enabled by the DTA as an opportunity the researcher has to learn about a phenomenon while they ontologically change themselves as the result of world texts.
\end{abstract}

Keywords: Discursive Textual Analysis; Text, Hermeneutics.

\section{Introdução}

Há quase 20 anos, a Análise Textual Discursiva (ATD) tem despontado como uma metodologia de análise qualitativa de interesse em pesquisas de diversas áreas do conhecimento. Utilizam-se da ATD pesquisas das áreas de Educação (ANDRADE; AQUINO; AZEVEDO, 2019), Ensino (FERREIRA; MUENCHEN; AULER, 2019), Saúde (MAZUR; GIORDANI; NETO, 2019; EBLING; SILVA, 2020), Ciências Sociais (MEDEIROS; AMORIM, 2017; ALMEIDA; ALVES, 2018), entre outras.

\footnotetext{
${ }^{1}$ Doutor em Educação em Ciências: Química da Vida e Saúde pela Universidade Federal do Rio Grande (FURG). Professor Adjunto do Departamento de Sociais e Humanas da Universidade Federal do Paraná (UFPR), Palotina, PR, Brasil. E-mail: robson.simplicio@ufpr.br
} 
Ao buscarmos "Análise Textual Discursiva” no Google Acadêmico, obtemos um resultado maior do que 8500 ocorrências. O livro que apresenta a metodologia Análise Textual Discursiva de Moraes e Galiazzi (2007) foi citado em 2891 trabalhos acadêmicos $^{2}$. O número de produções que se dedicam a estudar a ATD ou a utilizá-la já é muito difícil de acompanhar. A importância numérica é apenas um dos fatores que evidenciam a relevância da ATD no cenário da pesquisa qualitativa e que justifica a produção de um dossiê que especificamente dela trate.

Apesar do livro inaugural Análise Textual Discursiva ter sido publicado apenas em 2007, o marco textual de apresentação dessa metodologia pode ser considerado a publicação "Uma tempestade de luz: a compreensão possibilitada pela análise textual discursiva" (MORAES, 2003) na Revista Ciência \& Educação no início dos anos 2000. Este texto abre o livro de Análise Textual Discursiva (MORAES; GALIAZZI, 2007) que foi reeditado mais duas vezes (MORAES; GALIAZZI, 2011, 2016).

No "Uma Tempestade de Luz", o Professor Roque Moraes inicia a fundamentação da Análise Textual Discursiva. Apesar do texto ter sido publicado em 2003, o google acadêmico anuncia versões com títulos similares em anos anteriores:

- MORAES, R. Uma tempestade de luz. Porto Alegre: Edipucrs, [no prelo], 1999.

- MORAES, R. Uma tempestade de luz: a compreensão possibilitada pela análise textual qualitativa. Faculdade de Educação. Porto Alegre: PUC, 2001.

- MORAES, R. Uma tempestade de luz: a compreensão possibilitada pela análise textual discursiva, 2001. Apostila da disciplina "Análise Qualitativa de Informações Discursivas", 2003.

- MORAES, R. Uma tempestade de luz: a compreensão possibilitada pela análise textual discursiva, 2001. Apostila da disciplina Análise Qualitativa de Informações Discursivas, Mestrado em Educação Ambiental, FURG, Rio Grande, 2004. 23p.

Tratam-se de textos possivelmente preliminares, com algumas variações no nome que parecem ter circulado por algumas instituições em que o Professor Roque Moraes atuava antes da publicação oficial em nível nacional em 2003. As referências também evidenciam as parcerias de elaboração da ATD, especialmente, quando consideramos o uso do texto em uma apostila no mestrado em Educação Ambiental na Universidade

\footnotetext{
${ }^{2}$ Buscas realizadas em outubro de $2020 \mathrm{em}$ https://scholar.google.com.br/.
} 
Federal do Rio Grande (FURG), onde a Professora Maria do Carmo Galiazzi, co-autora do livro de ATD, atua.

O artigo de vinte e uma páginas foi citado quase 1400 vezes até a escrita desse artigo. É estruturado com uma introdução, quatro seções com algumas subseções em cada, nas quais Moraes (2003) apresenta os focos da ATD - 1. Desmontagem dos textos: desconstrução e unitarização; 2. Estabelecimento de relações: o processo de categorização; 3. Captando o novo emergente: expressando as compreensões atingidas; 4. Auto-organização: um processo de aprendizagem viva - e finaliza com uma seção de considerações finais. Assim, Moraes (2003) sinaliza neste texto etapas metodológicas, anuncia vinculações filosóficas e indica finalidades de utilização da Análise Textual Discursiva.

Podemos dizer que o texto "Uma tempestade de luz: a compreensão possibilitada pela análise textual discursiva" faz parte da tradição escrita da Análise Textual Discursiva. Entendemos tradição escrita no sentido de Gadamer (1960/2015), no qual:

\begin{abstract}
A tradição escrita não é apenas uma parte de um mundo passado, mas já sempre se elevou acima deste, na esfera do sentido que ela enuncia. Trata-se da idealidade da palavra que todo elemento de linguagem eleva acima da determinação finita e efêmera, própria aos restos de existências passadas. $\mathrm{O}$ portador da tradição não é este manuscrito como uma parte do passado, mas a continuidade da memória. Através dela, a tradição se converte numa parte do próprio mundo e, assim, o que ela nos comunica pode chegar imediatamente à linguagem. Onde uma tradição escrita chega a nós, não só conhecemos algo individual, mas se faz presente em nossa pessoa uma humanidade passada em sua relação universal (GADAMER, 2015, p. 505).
\end{abstract}

Trazemos à continuidade da memória o texto "Uma Tempestade de Luz", na intenção de, neste retorno à tradição, melhor compreender a proposição da Análise Textual Discursiva.

Em oportunidades anteriores, buscamos compreender conceitos que fazem parte da tradição de linguagem da ATD em coautoria com a Professora Maria do Carmo Galiazzi. Já nos desafiamos a compreender o que é a hermenêutica na ATD (SOUSA; GALIAZZI, 2016), o que vem a ser a categoria, método e sistema na ATD (SOUSA; GALIAZZI, 2017), a ideia do compreender na ATD (SOUSA; GALIAZZI, 2018), a dialética na ATD (GALIAZZI; SOUSA, 2019) e o fenômeno na ATD (GALIAZZI; SOUSA, no prelo). Desafiamo-nos, neste artigo, a melhor compreender o que vem o ser o texto na Análise Textual Discursiva. Apresentamos, portanto, um exercício de metatexto que emergiu a partir da análise do texto "Uma tempestade de luz: a compreensão possibilitada pela análise textual discursiva". 


\section{Uma Análise Textual Discursiva da Análise Textual Discursiva: Caminhos Metodológicos}

Realizamos a Análise Textual Discursiva no texto "Uma Tempestade de Luz: a compreensão possibilitada pela análise textual discursiva”. Utilizamos como corpus de análise o texto publicado no livro inaugural (MORAES; GALIAZZI, 2007). Conforme orienta a metodologia, ao definir o corpus de análise, inicia-se o processo de unitarização que é identificação de unidades de significado (US) no texto. Às US, atribuíram-se códigos conforme a ocorrência no texto: US1.X, em que US é a unidade de significado, 1 é referente ao capítulo 1 do livro e $\mathrm{X}$ é o algarismo arábico que indica a ordem de ocorrência da unidade de significado. Os códigos das US serão apresentados ao longo da descrição realizada no metatexto.

Para o envolvimento com o corpus de análise, partimos da pergunta fenomenológica “O que é isto: o texto na Análise Textual Discursiva?”. O perguntar fenomenológico carrega um movimento de percepção do percebido, ao mesmo tempo que apresenta um estranhamento frente a ele. É um exercício de dar-se conta e nele estabelecer uma abertura às emergências do fenômeno em análise, neste caso, o texto na ATD.

Após o processo de unitarização e da identificação de 58 US, passamos à etapa de categorização. Nesta análise, foram realizadas a categorização inicial e a categorização final. $\mathrm{Na}$ categorização inicial, aproximam-se US com sentidos próximos. Na categorização final, agregam-se categorias iniciais aproximáveis. Nesse processo, gerase um parágrafo-síntese para cada categoria final (MORAES; GALIAZZI, 2007).

Os parágrafos-síntese elaborados a partir das categorizações constituirão o metatexto, processo de descrição das categorias e subcategorias e interpretação do descrito, trazendo à baila interlocutores que possibilitem dialogar textualmente (MORAES; GALIAZZI, 2007). Trata-se de um processo de ampliação do já sabido, buscando por emergências compreensivas acerca do fenômeno texto na ATD.

Da presente análise, emergiram 3 categorias finais acerca do texto na ATD: i. $O$ Texto para a ATD: Produções Linguísticas de Múltiplas Interpretações acerca de um Fenômeno; ii. O Tratamento Analítico do Texto na Análise Textual Discursiva: da Atitude Fenomenológica à Interpretação Textual; iii. A Construção do Metatexto na ATD: Estrutura, Organização, Autoria e Aprendizagem sobre um Fenômeno. Estas são as categorias que serão apresentadas a seguir. 


\section{Um Metatexto sobre o Texto na Análise Textual Discursiva}

Nas próximas seções, apresentamos as três categorias que emergiram do processo de Análise Textual Discursiva sobre o capítulo 1 do livro homônimo (MORAES; GALIAZZI, 2007). A primeira categoria foi intitulada "O Texto para a Análise Textual Discursiva: Produções Linguísticas de Múltiplas Interpretações acerca de um Fenômeno" e trata mais detidamente do que vem a ser o texto dentro da metodologia de análise que investigamos. A segunda categoria, "O Tratamento Analítico do Texto na Análise Textual Discursiva: da Atitude Fenomenológica à Interpretação Textual", trata dos caminhos analíticos pelos quais passam os textos na ATD, o que nos dizem sobre como a metodologia caracteriza os textos estudados/construídos. Na terceira e última categoria nomeada "A Construção do Metatexto na Análise Textual Discursiva: Estrutura, Organização, Autoria e Aprendizagem sobre um Fenômeno", apresenta-se o metatexto como um texto construído a partir da metodologia.

Como prevê a própria ATD, a construção do metatexto é realizada a partir de movimentos de descrição e interpretação. Como movimento descritivo, partimos das categorias e subcategorias que são elaboradas ao longo da análise. Carregamos nelas o material empírico que acaba por dar validade à descrição. Como movimento interpretativo, permitimo-nos articular, neste texto, interlocutores que tratam o texto sob um caráter hermenêutico. Justificamos esta escolha, pois já está anunciada a relação da ATD à hermenêutica, especialmente, a Hermenêutica Filosófica de Hans-Georg Gadamer (SOUSA; GALIAZZI, 2016). Trazemos intérpretes do mesmo filósofo para um diálogo ampliado do que vem a ser um texto para a ATD. Portanto, apresentamos a seguir um metatexto sobre o texto na Análise Textual Discursiva.

\section{O Texto para a Análise Textual Discursiva: Produções Linguísticas de Múltiplas Interpretações acerca de um Fenômeno}

Após a realização da análise, apresenta-se o seguinte parágrafo-síntese para essa categoria: Para a ATD, os textos são produções linguísticas referentes a um determinado fenômeno. Podem ser produções escritas, imagens ou outras expressões linguísticas. $O$ texto não é objetivo em seus significados e, portanto, possibilita múltiplas leituras, interpretações e a construção de múltiplos sentidos simbólicos e significados que variam conforme diferentes teorias que a leitura carrega. Na ATD, os textos compõem o corpus de análise que pode ser produzido intencionalmente ou a partir de textos já existentes. 
Esta categoria se apresenta como uma tentativa de elaboração de um conceito de texto para a ATD, ainda resguardando os procedimentos de análise a serem realizados nos materiais textuais. Trata-se daquilo que o texto é e o que ele proporciona.

Apresenta-se o texto como uma produção linguística sobre um fenômeno, como evidenciado nas unidades de significado a seguir: US1.13. Os textos são produções linguísticas, referentes a determinado fenômeno e originadas em um determinado tempo e contexto; US1.15. Documentos textuais da análise constituem significantes a partir dos quais são construídos significados relativos aos fenômenos investigados; US1.14. [Textos] são vistos como produções que expressam discursos sobre diferentes fenômenos e que podem ser lidos, descritos e interpretados, correspondendo a uma multiplicidade de sentidos que a partir deles podem ser construídos.

Os textos são entendidos como produções lingüísticas, referentes a determinado fenômeno e originadas em um determinado tempo e contexto. São vistos como produções que expressam discursos sobre diferentes fenômenos e que podem ser lidos, descritos e interpretados, correspondendo a uma multiplicidade de sentidos que a partir deles podem ser construídos. Os documentos textuais da análise constituem significantes a partir dos quais são construídos significados relativos aos fenômenos investigados (MORAES; GALIAZZI, 2007, p. 16).

Quando se apresenta que um texto na ATD é uma produção acerca de determinado fenômeno, trata-se de uma produção textual acerca de algo a ser pesquisado, estudado, analisado. Ou seja, ali no texto se encontra (ou se espera encontrar) um fenômeno de interesse para a investigação. Entretanto, esse encontro é para além de uma manutenção da relação sujeito/objeto. Caracteriza-se mais como uma relação entre um fenômeno e o percebido que são indissociáveis nas experiências sob análise, ou seja, é um exercício fenomenológico (BICUDO, 2011). Na experiência com um fenômeno que nos mexe e nos mobiliza, carregamos nossos preconceitos, que podem ser confirmados, questionados, modificados, ampliados ou superados a partir do envolvimento com a investigado. Isso porque:

(...) um texto, um livro é um tu diante de nós, que nos interpela, tem algo a nos dizer e pode questionar nossos projetos prévios de sentido, nossos preconceitos, levando a revisá-los. A leitura é uma experiência que exige quebrar a resistência para abrir-se ao texto, para deixar valer a palavra do autor. Esse diálogo com o texto é feito a partir de um horizonte em que atuam os preconceitos e que são, como foi afirmado anteriormente, o limiar de acesso à leitura. A tradição age como um tu, que nos interroga, que nós não controlamos e que possibilita ampliar nosso horizonte interpretativo (HERMANN, 2010, p. 72).

Somos sujeitos históricos e imersos em uma tradição que nos possibilita interpretar os fenômenos dentro do horizonte compreensivo que estamos inseridos. Com 
isso, “(...) o sentido do texto ultrapassa o autor, está entre o texto e o leitor. A hermenêutica defenderá, então, a perspectiva do próprio sujeito na participação viva das tradições históricas que nos determinam" (HERMANN, 2010, p. 70). Nossa historicidade passa, portanto, pelo nosso modo de interpretar os textos do mundo e orienta nossa atribuição de sentidos ao lido e interpretado.

\begin{abstract}
Nossa compreensão tanto de um texto como de uma situação se dá no horizonte de uma tradição à qual pertencemos, à qual estamos sujeitos, de modo que a historicidade é condição de possibilidade de nossa compreensão. As considerações sobre a pré-estrutura da compreensão lançam outra perspectiva para o ato de ler. Ou seja, ele não se realiza sem o peso da historicidade, daquilo que constitui nossos esquemas interpretativos prévios. Assim, a précompreensão é o limiar que dá acesso à leitura do texto (HERMANN, 2010, p. 71).
\end{abstract}

No processo de leitura e busca de compreensão de um texto carregamos précompreensões e elaboramos sentidos ao que se mostra. Para Gadamer, a compreensão humana é sempre determinada historicamente e é sempre dada na pré-compreensão. A pré-compreensão é a estrutura que envolve nosso conjunto de preconceitos, nossa pertença a uma situação histórica, a uma tradição, que vincula o intérprete e é interpretada junto no mesmo processo histórico (LAWN; KEANE, 2011). A pré-compreensão tem, portanto, um caráter existencial e é condição para uma experiência hermenêutica, ou seja, para uma experiência interpretativa do mundo em que projetamos as expectativas conceituais que carregamos. Nesse sentido, o leitor/pesquisador não é, portanto, isento no processo de experiência de um fenômeno, ele carrega consigo suas pré-compreensões. Não podemos querer uma isenção no processo de análise deste mesmo fenômeno.

\footnotetext{
Assim, ler e compreender um texto ou uma situação consiste na elaboração de um projeto prévio de sentido, que será substituído por novos projetos, até que opiniões equivocadas sejam superadas. Portanto, nunca temos uma compreensão desde já fechada. Há a necessidade de abrir-se à opinião do outro (expor-se), entregar-se ao texto. Essa receptividade é incompatível com um autocancelamento do intérprete; ao contrário, uma consciência hermenêutica pressupõe a incorporação das opiniões prévias e pré-conceitos, pelas quais o leitor se torna ativo na produção de sentido. Aqui se evidencia, em sua inteireza, a diferença entre a tradição epistemológica do iluminismo, com suas pretensões de isenção do sujeito cognoscente, e a experiência hermenêutica do compreender (HERMANN, 2010, p. 71).
}

Uma outra ideia que se apresenta é a de que as produções textuais - escrita, imagem ou outras expressões linguísticas (US1.16) - não são objetivas em seus significados e isso possibilita diferentes interpretações, leituras e múltiplos significados, como apresentado nas seguintes US: US1.3. Todo texto possibilita uma multiplicidade de leituras que estão relacionadas às intenções dos autores, aos referenciais teóricos e aos campos semânticos em que se inserem; US1.9. A polissemia de um texto pode dar origem 
a diferentes tipos de leituras, algumas com interpretações compartilhadas entre diferentes leitores; US1.23. Há múltiplas leituras de um texto em que uma mesma unidade pode ser lida de diferentes perspectivas, com múltiplos sentidos, e, por isso, pode ser classificada em mais de uma categoria, ainda que com sentidos diferentes.

Ao iniciar uma discussão de análise qualitativa, precisamos ter presente a relação entre leitura e interpretação. Se um texto pode ser considerado objetivo em seus significantes, não o é nunca em seus significados. Todo texto possibilita uma multiplicidade de leituras, leituras essas relacionadas com as intenções dos autores, com os referenciais teóricos dos leitores e com os campos semânticos em que se inserem (MORAES; GALIAZZI, 2007, p. 13).

Na leitura e interpretação de um texto, estabelece-se um diálogo entre o leitor e o texto. Em um diálogo que se considera autêntico, há um enredamento entre os interlocutores que entram em um jogo interpretativo permeado pelo movimento de pergunta e resposta (GADAMER, 2015). Um texto, ao mesmo tempo que carrega consigo respostas a muitos questionamentos, está constituído e aberto como uma estrutura de questionamento do que se apresenta. Assim, o texto está estruturalmente disponível ao diálogo com o leitor.

A leitura, como interpretação, é um diálogo entre o texto e leitor que abre sentidos. Esse diálogo tem pressuposta "a estrutura da pergunta e resposta". O texto interroga o leitor e abre possibilidades de sentido que vão além do próprio texto. A pergunta traz a questionabilidade de algo, e o compreender do texto é resultado do processo de perguntar. (...) Quando lemos, o texto nos faz perguntas, que exigem deixar o tema vir à luz. O diálogo entre o leitor e o texto possibilita condições de reflexão sobre um entendimento ainda não disponível, ou seja, oportuniza ao leitor fazer uma autorreflexão sobre seus próprios pontos de vista. (...) $\mathrm{O}$ texto pergunta ao leitor e a pergunta abre o horizonte do outro, conduzindo o leitor para fora de suas próprias reservas (HERMANN, 2010, p. 73).

Em consenso e numa aproximação de perspectivas com a autora supracitada, Gadamer amplia e conceitua texto:

O conceito de texto só se constitui num conceito central na estrutura da linguagem no e a partir do contexto da interpretação; o que caracteriza o conceito de texto é que somente se apresenta à compreensão no contexto da interpretação e como o que se dá realmente. (...) o intérprete de um texto pergunta pelo que há propriamente nele. Essa pergunta poderá ter uma resposta não isenta de pressuposições e preconceitos, uma vez que aquele que pergunta busca uma confirmação direta de suas suposições. Mas nesse apelo ao que há no texto, este aparece como um ponto de referência fixo frente à problematicidade, arbitrariedade ou, no mínimo, à pluralidade de possibilidades interpretativas que se dirigem ao texto (GADAMER, 2012, p. 277).

Colocamo-nos, assim, em acordo com Hermann (2010) quando escreve que a leitura de textos é uma experiência hermenêutica, uma experiência interpretativa, de esclarescimento dos pressupostos teóricos do texto e das suas tradições culturais. Para a 
autora é preciso que o leitor se confronte com essas suposições e revise a si como intérprete do que está sendo lido/interpretado. É aquilo que Gadamer (2015) chama de “fusão de horizontes" de compreensão.

\section{O Tratamento Analítico do Texto na Análise Textual Discursiva: da Atitude} Fenomenológica à Interpretação Textual

A segunda categoria que emergiu da análise foi uma vinculada aos procedimentos analíticos pelos quais passa um texto na ATD. Entendemos que os procedimentos pelos quais o corpus de análise passa dão pistas ao que é o texto nessa metodologia de análise. Assim ficou o parágrafo-síntese correspondente a esta categoria:

Na ATD, a leitura de textos pelo pesquisador é um exercício de atitude fenomenológica de atribuição de sentidos e significados aos materiais textuais que evidenciam a perspectiva do outro. Os sentidos dos textos são percebidos a partir da fragmentação ou desconstrução, cuja percepção absoluta nunca é atingida, e são desmontados no processo de unitarização com foco nas partes que os compõem. Uma mesma unidade pode ser classificada em mais de uma categoria por seus múltiplos sentidos que, posteriormente, são descritos e interpretados. Toda leitura e toda análise textual já é uma interpretação e, por isso, o pesquisador precisa se assumir autor das interpretações construídas ao analisar os textos. Isso porque interpretar é construir novos sentidos e compreensões aprofundadas, indo além da descrição e ampliar a compreensão dos fenômenos que se investiga e o campo teórico com que trabalha.

A partir da análise realizada, apresenta-se como uma demanda da Análise Textual Discursiva uma atitude fenomenológica do pesquisador em relação aos materiais textuais. Isso está explícito na US1.10. A leitura de textos é um exercício de uma atitude fenomenológica de colocar entre parênteses as próprias ideias e teorias e exercitar uma leitura a partir da perspectiva do outro. Os textos, neste caso, estão disponíveis ao leitor/pesquisador que, embora carregue consigo seus pressupostos, precisa momentaneamente e esforçosamente suspendê-los, no que se considera uma atitude fenomenológica. Em uma atitude fenomenológica nos tornamos observadores de um jogo, espectadores, uma contemplação dos envolvimentos que temos com o mundo e com as coisas nele. Não se trata de participar do mundo, mas de contemplar o que é ser um participamente no mundo e em suas manifestações (SOKOLOWSKI, 2014). Trata-se de por entre colchetes o mundo e todas as coisas no mundo. Isso quer dizer que "quando 
colocamos entre colchetes o mundo ou algum objeto particular, não o votamos a mera aparência, uma ilução, mera ideia ou qualquer outro tipo de impressão meramente subjetiva" (SOKOLOWSKI, 2014, p. 58).

$\mathrm{Na}$ aproximação ao corpus textual na ATD, mostra-se necessária essa suspensão momentânea que podemos interpretar como um movimento de "abertura ao outro (texto) implica fazer valer algo que o outro tem a dizer, superando o dogmatismo. Na experiência hermenêutica, isso significa reconhecer as pretensões da tradição, contra a certeza metodológica" (HERMANN, 2010, p. 72).

A percepção fenomenológica é ainda estimulada pela fragmentação do texto, no processo de unitarização, como mostrado em: US1.21. [Na ATD,] os textos passam por processo de desmontagem ou desintegração, a desconstrução ou unitarização do “corpus”, para focar nos detalhes e nas partes que os compõem. US1.22. Pretende-se perceber os sentidos dos textos a partir da fragmentação ou desconstrução, compreendendo que uma percepção absoluta nunca é atingida.

\begin{abstract}
A desconstrução e unitarização do "corpus" consistem num processo de desmontagem ou desintegração dos textos, destacando seus elementos constituintes. Significa colocar o foco nos detalhes e nas partes componentes dos textos, um processo de decomposição que toda análise implica. Com essa fragmentação ou desconstrução pretende-se conseguir perceber os sentidos dos textos em diferentes limites de seus pormenores, ainda que compreendendo que um limite final e absoluto nunca é atingido. É o próprio pesquisador que decide em que medida fragmentará seus textos, podendo daí resultarem unidades de análise de maior ou menor amplitude (MORAES; GALIAZZI, 2007, p. 18).
\end{abstract}

Para Gadamer, a destruição/desfragmentação se aproxima de um exercício de “diálogo vivo", em uma acepção positiva, que visa reinscrever um conceito tornado vazio a partir de onde ele veio e que lhe dá todo sentido (GRONDIN, 2012). De modo a ampliar esta compreensão e melhor pormenorizando-a,

\begin{abstract}
(...) o desconstrutivismo opera com uma estratégia de leitura que ultrapassa a intenção do autor, deslizando no texto, em busca de outro significado, de aporias que traem as intenções aparentemente explícitas do texto. De acordo com essa estratégia, não há sentidos preestabelecidos, senão que se há reinventá-los marginalmente. O texto é afetado pela ambiguidade, utiliza-se de metáforas, figuras diversas para opor-se ao mito idealista de que é possível uma fixação de sentido (HERMANN, 2010, p. 68).
\end{abstract}

Ainda na fragmentação, uma unidade de significado pode ser classificada em mais de uma categoria por seus múltiplos sentidos que, posteriormente, são descritos e interpretados: US1.23. Há múltiplas leituras de um texto em que uma mesma unidade pode ser lida de diferentes perspectivas, com múltiplos sentidos, e, por isso, pode ser classificada em mais de uma categoria, ainda que com sentidos diferentes; US1.24. A 
partir dos múltiplos sentidos em um texto, é possível construir vários conjuntos de categorias a partir de um mesmo conjunto de informações que mostram alguns sentidos que o corpus permite construir.

Apresenta-se ainda a ideia de que os múltiplos sentidos de toda leitura e toda análise textual estão vinculados ao ato de interpretar. Assim, o pesquisador precisa se assumir autor das interpretações construídas ao analisar os textos, construir novos sentidos e compreensões aprofundadas, indo além da descrição e ampliar a compreensão dos fenômenos que se investiga e o campo teórico com que trabalha. Esta ideia está explícita nas US: US1.19. A partir dos textos analisados, exige-se do pesquisador que se assuma como autor das interpretações que constrói.; US1.34. Para a estruturação de um [meta]texto coerente e consistente, é preciso construir argumentos aglutinadores como uma das contribuições mais significativas e originais do pesquisador.; US1.49. Os metatextos não devem ser entendidos como modos de expressar algo já existente nos textos, mas como construções do pesquisador e seu intenso envolvimento.; US1.50. As descrições, as interpretações e as teorizações expressas como resultados da análise, não se encontram nos textos para serem descobertas, mas constituem resultado de um esforço de construção intenso e rigoroso do pesquisador.; US1.44. Na análise textual, interpretar é construir novos sentidos e compreensões, afastando-se do imediato e exercitado uma abstração. Interpretar é um exercício de construir e de expressar uma compreensão mais aprofundada, indo além da expressão de construções obtidas a partir dos textos e de um exercício meramente descritivo. É nossa convicção de que uma pesquisa de qualidade necessita atingir essa profundidade maior de interpretação. Ou trazendo a citação exata:

\begin{abstract}
No contexto da análise textual interpretar é construir novos sentidos e compreensões afastando-se do imediato e exercitando uma abstração. Interpretar é um exercício de construir e de expressar uma compreensão mais aprofundada, indo além da expressão de construções obtidas a partir dos textos e de um exercício meramente descritivo. É nossa convicção de que uma pesquisa de qualidade necessita atingir essa profundidade maior de interpretação (MORAES; GALIAZZI, 2007, p. 36).
\end{abstract}

Apresenta-se aqui a centralidade da interpretação como processo de compreensão aprofundada de um texto/fenômeno. Para Gadamer (2012), a interpretação, no sentido literal da palavra interpres, expressava originalmente uma relação mediadora, uma função de intérprete entre pessoas que falam idiomas diferentes, ou seja, um tradutor. O tradutor tem a responsabilidade de transpor um sentido a ser compreendido para o horizonte compreensivo de outro interlocutor, para o mundo do outro. Gadamer (2012, 2015) ilustra, a partir do fenômeno da tradução, justamente os processos de diálogo entre 
interlocutores que estabelecem um diálogo autêntico, em busca de consenso. Constitui, portanto, nossa estrutura mais elementar de busca de compreensão do outro e do mundo. É por isso que para ele, a interpretação "constitui, antes, a estrutura originária do ser-nomundo" (GADAMER, 2012, p. 276).

O pesquisador que traduz e interpreta um texto produz um avanço metodológico, ou seja, o texto pode ser entendido como um conceito hermenêutico. Desse modo,

\begin{abstract}
A estreita correlação entre texto e interpretação fica clara quando se leva em conta que nem sequer um texto tradicional é sempre uma realidade dada previamente à interpretação. Muitas vezes, é a interpretação que leva à criação crítica do texto. $\mathrm{O}$ esclarescimento dessa relação interna entre interpretação e texto constitui um avanço metodológico. (...) o "texto" deve ser entendido aqui como um conceito hermenêutico. Isso significa que não é visto a partir da perspectiva da gramática e da linguística, ou seja, como produto final, buscado pela análise de sua produção. (...) Para a ótica hermenêutica, ao contrário, a compreensão do que o texto diz é a única coisa que interessa. O funcionamento da linguagem é uma simples condição prévia. O primeiro pressuposto é que uma manifestação possa ser ouvida ou que uma fixação por escrito possa ser decifrada para que se possa compreender o que foi dito e escrito (GADAMER, 2012, p. 278-279).
\end{abstract}

Assim, o texto na ATD pode ser entendido como um conceito hermenêutico acerca de um fenômeno/manifestação que possa ser lido e interpretado. É, portanto, uma realidade dada à interpretação e o que nele está é o que de fato interessa. Ou seja, na ATD “(...) a tradução realizada pelo pesquisador é o meio pelo qual o fenômeno se mostra, não na individualidade do pesquisador, mas na tradução das vozes que dizem sobre o fenômeno interpretado e que são reconhecidas por quem interpreta" (SOUSA; GALIAZZI, 2016, p. 46). O pesquisador tradutor-intérprete que na ATD se coloca disponível aos textos do mundo acerca de um fenômeno em investigação entra em um jogo interpretativo a partir do que nele se apresenta e sobre ele percebe diferentes sentidos interpretáveis.

\title{
6 A Construção do Metatexto na Análise Textual Discursiva: Estrutura, Organização, Autoria e Aprendizagem sobre um Fenômeno
}

Nesta categoria, aparece o metatexto na ATD. O metatexto - que é um texto construído a partir do tratamento analítico discutido anteriormente - diz muito sobre o que é um texto para a ATD com suas características estruturais, de organização, autoria e finalidade. Assim fica o parágrafo-síntese dessa categoria:

Os metatextos são a descrição e interpretação dos fenômenos investigados. Eles são estruturados por meio das categorias e subcategorias da análise e podem ser mais descritivos, próximos ao corpus, ou mais interpretativos, mais afastados do material 
empírico. Entretanto, sua validade e confiabilidade são construídas justamente a partir da realidade empírica, com citações do corpus. Estruturalmente, o metatexto necessita de uma introdução e fechamento de qualidade. A tese geral é o elemento organizador de texto, que foge, assim, da fragmentação e possibilita a autoria. Trata-se, portanto, de o pesquisador se assumir autor de seus argumentos, o que dá qualidade ao texto. Não se trata de um retorno aos textos originais, mas um novo texto com a compreensão do pesquisador sobre os originais. Nesse caso, a compreensão é mais do que a soma das categorias, mas algo que o pesquisador tem a dizer sobre o fenômeno investigado. $O$ metatexto explicita uma compreensão mais aprofundada, com clareza e rigor e se caracteriza pela incompletude e crítica constante, pois o autor precisa ajudar o leitor a compreender seu metatexto. A compreensão possibilitada pela construção do metatexto é reiterativa, de movimento espiralado e de retorno aos entendimentos na busca de sentidos, além de ser uma oportunidade de aprender sobre os fenômenos investigados.

A primeira ideia emergente desta categoria é a de que o metatexto é um texto de descrição e interpretação de um fenômeno elaborado a partir das categorias e subcategorias analíticas. Corroboram com essa ideia, as US: US1.28. Os metatextos são constituídos de descrição e interpretação, representando um modo de teorização sobre os fenômenos investigados. US1.47. A produção de um metatexto, combinando descrição e interpretação, constitui-se num esforço para expressar intuições e entendimentos atingidos a partir da impregnação intensa com o "corpus" da análise.; US1.27. A estrutura textual [do metatexto] é construída por meio das categorias e subcategorias resultantes da análise; US1.42. Descrever é apresentar as categorias e subcategorias, fundamentando e validando essas descrições a partir de interlocuções empíricas ou ancoragem dos argumentos em informações retiradas dos textos. Empiricamente, podemos citar do livro de Análise Textual Discursiva:

\footnotetext{
A produção de um meta-texto, combinando descrição e interpretação, uma das formas de caracterizar a análise textual discursiva, constitui-se num esforço para expressar intuições e entendimentos atingidos a partir da impregnação intensa com o "corpus" da análise. É, portanto, um esforço construtivo no sentido de ampliar a compreensão dos fenômenos investigados. É um movimento sempre inacabado de procura de mais sentidos, de aprofundamento gradativo da compreensão dos fenômenos (MORAES; GALIAZZI, 2007, p. 37).
}

Em termos estruturais, o metatexto pode ser mais descritivo: US1.30. Alguns [meta]textos serão mais descritivos, mantendo-se mais próximos do "corpus" analisado; US1.39. Descrever constitui-se num movimento de produção textual mais próximo do empírico, sem envolver um exercício interpretativo mais aprofundado.; US1.40. a 
descrição se constitui em exposição de ideias de uma perspectiva próxima de uma leitura imediata, cuidadosa e detalhada.; ou ou mais interpretativo, como nos mostram: US1.31. Outros [metatextos] serão mais interpretativos, pretendendo um afastamento maior do material original num sentido de abstração e teorização mais aprofundado; US1.41. À medida em que nos afastamos da realidade mais imediata do texto, estamos nos envolvendo gradativamente num exercício interpretativo. No texto original:

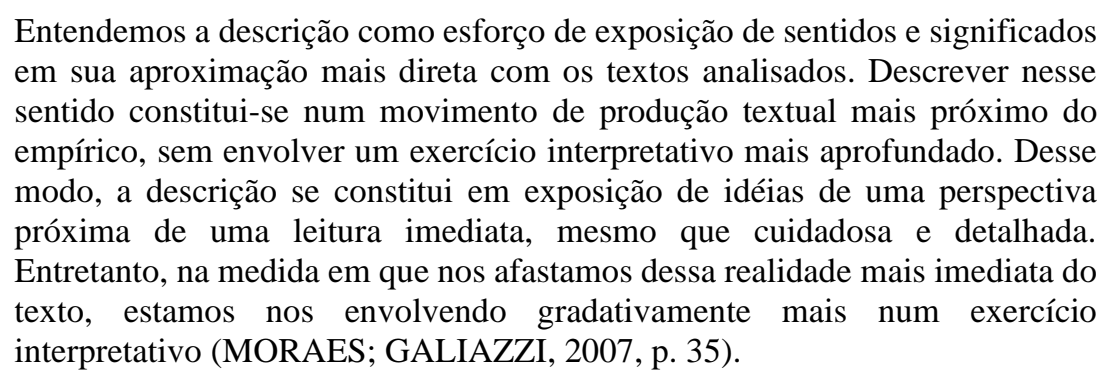

Independente de uma construção de metatexto mais descritiva ou interpretativa, é necessário que sua construção seja válida e confiável, como nos mostram: US1.51. Os produtos de uma análise textual necessitam ser válidos e confiáveis, o que significa que quando submetidos à crítica dos autores do corpus, estes precisam estar contemplados nos resultados.; US1.52. A validade de um metatextos se constrói a partir da ancoragem dos argumentos na realidade empírica por meio de citações de elementos do corpus. Além disso, é preciso considerar a introdução e encerramento do metatexto e, principalmente, a tese geral que possibilida a articulação entre as US que anteriormente encontravam-se misturadas em um caldeirão de ideias. As US que mostram essa ideia são: US1.36. Ao corpo principal de um metatextos necessita reunir-se uma introdução e um fechamento de qualidade. A introdução vista como "dizer o que vem depois" e o fechamento, entendido como "dizer o que veio antes" são elementos essenciais para a construção de textos claros e de fácil leitura; US1.35. A tese geral servirá de elemento estruturador e organizador de todos os elementos componentes do texto, permitindo não apenas fugir da excessiva fragmentação, mas também possibilitando ao pesquisador assumir-se efetivamente autor de seu texto.

São os elementos destacados acima que possibilitam que o pesquisador se assuma autor de sua interpretação acerca do fenômeno em investigação como em US1. 29. A qualidade dos textos resultantes das análises [metatexto] não depende apenas de sua validade e confiabilidade, mas é, também, consequência de o pesquisador assumir-se autor de seus argumentos. Além disso, trata-se de muito mais do que um retorno aos textos originais, mas uma reinterpretação com novas compreensões acerca do 
originalmente analisado: US1.26. A pretensão [do metatexto] não é o retorno aos textos originais, mas construção de um novo texto que tem sua origem nos textos originais $e$ que expressam a compreensão do pesquisador sobre os significados e sentidos construídos a partir deles.

As características de descrição e interpretação na ATD já foram esmiuçadas em trabalhos anteriores (SOUSA; GALIAZZI, 2016; 2017; 2018; SOUSA; GALIAZZI; SCHMIDT, 2016). De modo conciso, na análise com ATD, a descrição é um movimento na linguagem a partir do qual o sujeito que investiga perceba e se dê conta do modo como o fenômeno se mostra. Desse modo, o pesquisador, além do fato de buscar a escuta do fenômeno, ele passa a perceber suas pré-compreensões e preconceitos, confirmá-los, ampliá-los, suprimi-los ou ainda superá-los. Trata-se mais da construção de um mosaico do que de um quebra-cabeça, como confirmam Sousa e Galiazzi (2018). Só é possível que o pesquisador realize essas ações ao considerar uma abertura interpretativa ao fenômeno. Isto se dá especialmente pela perseguição de emergências teóricas, além daquelas do campo de conhecimento que o pesquisador está inserido. Assim, conseguese estabelecer um "movimento de ampliação de compreensões daquele que investiga e que modifica sua existência na linguagem acerca do fenômeno ontológico que se dedica compreender" (SOUSA; GALIAZZI, 2017, p. 51).

A compreensão construída pelo pesquisador ao longo de seu movimento analítico, é muito mais ampla do que a soma das categorias, mas amplia o que se sabe sobre o fenômeno em análise. Trata-se, portanto, de um aprofundamento acerca do que está em estudo, mesmo que o pesquisador tenha que lidar a incompletude da tarefa grandiosa de compreender um fenômeno. Seu papel envolve, com isso, possibilitar a compreensão para leitores com um processo de construção do metatexto de modo recursivo, espiralado de permanente retorno aos sentidos do que se estuda e sobre isso aprender mais. Confirmam essa ideia as seguintes US: US1.54. No metatexto, a compreensão emerge a partir de muito mais do que a soma das categorias, mas deve constituir-se a partir de algo importante que o pesquisador tem a dizer sobre o fenômeno que investigou, um argumento aglutinador ou tese que foram construídos pela impregnação com o fenômeno; US1.58. Na ATD, é essencial a construção de um texto em que cada uma de suas categorias ou partes seja perfeitamente integrada num todo. Para isso é importante que haja uma "tese" ou argumento central, capaz de possibilitar o encadeamento das partes no todo; US1.32. A produção textual na análise textual discursiva caracteriza-se por sua permanente incompletude e pela necessidade de crítica constante.; US1. 47. A 
produção de um metatextos é um esforço construtivo de ampliar a compreensão dos fenômenos investigados, um processo sempre inacabado de procura de mais sentidos, de aprofundamento gradativo da compreensão dos fenômenos; US1.48. A construção da compreensão possibilitada pela produção do metatextos é um processo reiterativo, movimento espiralado, em que retomam-se periodicamente entendimentos já atingidos na busca de mais sentidos. US1.38. A produção textual, mais do que simplesmente um exercício de expor algo já perfeitamente dominado e compreendido, é uma oportunidade de aprender. É um processo vivo, um movimento de aprendizagem aprofundada sobre os fenômenos investigados. Combina duas faces de um mesmo movimento, o aprender e o comunicar.; US1.57. Os movimentos metodológicos da ATD que geram os metatextos constituem um exercício de aprender que se utiliza da desordem e do caos para possibilitar a emergência de formas novas e criativas de entender os fenômenos investigados.

A produção textual, mais do que simplesmente um exercício de expor algo já perfeitamente dominado e compreendido, é uma oportunidade de aprender. É um processo vivo, um movimento de aprendizagem aprofundada sobre os fenômenos investigados. Combina duas faces de um mesmo movimento, o aprender e o comunicar (MORAES; GALIAZZI, 2007, p. 34).

Emerge aqui a ideia de que os movimentos de descrição e de interpretação necessitam de aprofundamento em suas elaborações. O pesquisador tem, portanto, na descrição densa que estabelecer um movimento dialético que o possibilite textualmente expressar sobre um fenômeno.

A considerarmos os múltiplos sentidos que se pode atribuir às palavras, frases, proposições e sentenças, é na descrição densa que o pesquisador pode perceber esta complexidade de sentidos que o leva ao movimento dialético de expressar o fenômeno enquadrado em uma teoria ou, de outro modo, a teorizar a partir da empiria estando aberto assim a encontrar teorias não esperadas, sendo esta condição expressa pela ideia de autoorganização. Em um modo ou outro, de um mais formal e estabelecido, de outro mais processual e auto-organizado e emergente é que fenômeno se mostra e com isso se expressa também a autoria do pesquisador (SOUSA; GALIAZZI, 2017, p. 535-536).

Aparece ainda a ideia de que a construção aprofundada do (meta)texto na ATD segue um movimento espiralado. Como apresentam Sousa e Galiazzi (2016), esse movimento espiralado de elaboração do texto está intimamente vinculado à ideia de círculo hermenêutico. Assim, na ATD,

(...) temos as noções de círculo hermenêutico e de espiral hermenêutica como movimentos de busca de compreensão que são recursivos, mas que não são "viciados". Neles, não é possível voltar para o ponto em que começou sem que o investigador carregue consigo suas pré-compreensões que são ampliadas e modificadas à medida que caminha na análise. (...) Os passos propostos na 
Análise Textual Discursiva são sinalizações que indicam o caminho em direção à compreensão (SOUSA; GALIAZZI, 2016, p. 51).

Independente da analogia utilizada para expressar a profundidade com a qual é realizada a análise com ATD, é preciso que seja densa e aprofundada. Só por este caminho é que se pode alcançar textualmente a tarefa prevista no "Tempestade de Luz" e cerne dessa metodologia: o pesquisador precisa aprender no processo de análise com a ATD.

Quando se compreende e assume que produzir um texto é um modo de aprender, também se compreende a necessidade de ir produzindo textos com reiteradas revisões, momentos em que se vai conseguindo expressar novos entendimentos construídos pelo autor ao longo do processo da escrita (MORAES, 2010, p. 145).

Interpretamos, a partir do evidenciado, que a tarefa de aprender com a ATD envolve considerar diferentes disposições que são atribuídas por Gadamer (2009) a um cientista hermenêutico $^{3}$. A primeira é a disposição da dúvida, que envolve que o pesquisador deseje ser capaz de identificar e questionar seus presuspostos e que a partir dessa disposição possibilite a reformulação desses. É utilizar a dúvida como orientadora do aperfeiçoamento da própria compreensão. Outra delas é a disposição de estar embebido, densamente imerso nos textos que dão sentido à análise, seja o corpus como material empírico, seja o metatexto em construção. Trata-se da disposição da distração, que ele chamou de ausência. A última envolve ainda a disposição à humildade ou modéstia de se dar conta de que a compreensão de um fenômeno nunca pode ser integralmente atingida dada a complexidade do que pode mostrar um fenômeno. Como pesquisador que se utiliza da ATD, é preciso concerbemos a tarefa hermenêutica de compreender um fenômeno como sempre parcial, limitada pelo nosso limite histórico e nossa existência em uma tradição. Ao considerarmos o texto como um conceito hermenêutico, é preciso considerarmos essas disposições ao lidar com ele, seja na leitura, seja na escrita.

\section{Uma Conclusão Aberta à Textualização}

$\mathrm{Na}$ releitura hermenêutica do texto "Uma tempestade de luz: a compreensão possibilitada pela análise textual discursiva", buscamos apresentar um exercício de ATD

\footnotetext{
${ }^{3}$ No texto "Sobre a originalidade da ciência", discurso proferido por Gadamer em um contexto pós-segunda guerra mundial e na reabertura da Universidade de Leipzig, o filósofo alertou que se todos os homens da ciência alemães tivessem buscado disposições hermenêuticas e se estas estivessem suficientemente estabelecidas, a vinculação ao regime nacional-socialista não teria representado para eles nenhuma tentação (GADAMER, 2009). O termo cientista hermenêutico, utilizado neste artigo, foi traduzido por Borda (2007) ao interpretar as disposições trazidas por Gadamer e aplicá-las à Educação em Ciências.
} 
acerca do que se apresenta como texto nessa metodologia de análise. Mostrou-se o texto como uma produção linguística que possibilita múltiplas interpretações ao se buscar compreender um fenômeno. O conceito de texto foi, então, associado à interpretação que é em si uma experiência hermenêuca, na busca de uma fusão de horizontes entre o leitor/pesquisador e o texto.

No modo de tratar o texto na ATD, aparece a inicialmente a necessidade de se ter uma atitude fenomenológica que se encaminha para uma interpretação textual. Nesse tratamento, podemos interpretar o pesquisador como um tradutor-intérprete dos textos do mundo acerca do fenômeno de interesse. Os sentidos atribuídos pelo pesquisador são elaborados pela tradição histórica que ele está imerso e cujo horizonte de compreensão é também por ela limitado. Resta ao pesquisador colocar-se no jogo interpretativo a partir do que nele se apresenta.

Construir um metatexto é também um modo de lidar com o texto na ATD. Apresenta-se como exigência dessa construção a descrição e a interpretação no texto em produção em movimentos circulares ou espirais de aprofundamento teórico. Os movimentos são para reforçar o caráter de aprendizagem que é central na ATD, o que me leva a articular as construções textuais com disposições hermenêuticas. Isto reforça, portanto, o caráter ontológico do processo analítico com ATD como um modo de lidar com os textos do mundo.

\section{Referências}

ALMEIDA, C. D.; ALVES, L. C. de S. Narrativas e experiências de vida de casal trans na fronteira. Conexão-Comunicação e Cultura, Caxias do Sul, v. 17, n. 34, p. 259-277, jul./dez. 2018.

ANDRADE, J. A. P. de.; AQUINO, S. F.; AZEVEDO, R. O. M. Implicações do conselho de classe no processo de ensino-aprendizagem: O lugar de onde falam os alunos. Revista Educação, Cultura e Sociedade, Sinop, v. 9, n. 1, p. 09-19, jan./jun. 2019.

BICUDO, M. A. V. Pesquisa Qualitativa segundo a visão fenomenológica. São Paulo: Cortez, 2011.

BORDA, E. J. Applying Gadamer's concept of disposition to science and science education. Science \& Education, Dordrecht, v. 16, n. 9-10, p. 1027-1041, fev. 2007.

EBLING, S. B. D.; SILVA, M. R. S. da. O consumo de álcool entre mulheres que vivem em contextos rurais. Rev. Bras. Enferm., Brasília, v. 73, supl. 4, e20190612, set. 2020. 
FERREIRA, M. V.; MUENCHEN, C.; AULER, D. Desafios e Potencialidades em Intervenções Curriculares na Perspectiva da Abordagem Temática. Ensaio: Pesquisa em Educação em Ciências, Belo Horizonte, v. 21, e10499, p. 1-22, abr. 2019.

GADAMER, Hans-Georg. Hermenêutica em retrospectiva. Petrópolis: Vozes, 2009.

GADAMER, Hans-Georg. Texto e Interpretação. In: GRONDIN, J. (org.). O pensamento de Gadamer. São Paulo: Paulus, 2012. p. 261-310.

GADAMER, Hans-Georg Verdade e método I: traços fundamentais de uma hermenêutica filosófica. 15. ed. Petrópolis: Editora Vozes, 2015.

GALIAZZI, M. do C.; SOUSA, R. S. de. A dialética na categorização da análise textual discursiva: o movimento recursivo entre palavra e conceito. Revista Pesquisa Qualitativa, São Paulo, v.7, n. 13, p. 01-22, abr. 2019.

GALIAZZI, M. do C.; SOUSA, Robson Simplicio de. O que é isso que se mostra: o fenômeno na análise textual discursiva? Atos de Pesquisa em Educação (FURB), Blumenau (SC), v.15, n. 4, p. 1167-1184, out./dez. 2020.

GRONDIN, J. Hermenêutica. São Paulo: Parábola Editorial, 2012.

HERMANN, N. M. A. Leitura e escrita no campo filosófico-educacional. Revista Trama Interdisciplinar, São Paulo, v. 1, n. 1, p. 65-82, abr. 2010.

MAZUR, S. M.; GIORDANI, A. T.; NETO, J. C. Repensar a Formação de Professores de Enfermagem: uma Perspectiva a Partir de uma Revisão Sistemática de Literatura. Revista de Ensino, Educação e Ciências Humanas, Londrina, v. 20, n. 1, p. 28-36, abr. 2019.

MEDEIROS, E. A. de; AMORIM, G. C. C. Análise textual discursiva: dispositivo analítico de dados qualitativos para a pesquisa em educação. Laplage em revista, Sorocaba, v. 3, n. 3, p. 247-260, ago. 2017.

MORAES, R. Uma tempestade de luz. Porto Alegre: Edipucrs, [no prelo], 1999.

MORAES, R. Uma tempestade de luz: a compreensão possibilitada pela análise textual qualitativa. Faculdade de Educação. Porto Alegre: PUC, 2001.

MORAES, R. Uma tempestade de luz: a compreensão possibilitada pela análise textual discursiva, 2001. Apostila da disciplina Análise Qualitativa de Informações Discursivas, Mestrado em Educação Ambiental, FURG, Rio Grande, 2004.

MORAES, R. Uma tempestade de luz: a compreensão possibilitada pela análise textual discursiva. Ciência \& Educação, Bauru, v. 9, n. 2, p. 191-211, out. 2003.

MORAES, R. O significado do aprender: linguagem e pesquisa na reconstrução de conhecimentos. CONJECTURA: filosofia e educação, Caxias do Sul, v. 15, n. 1, p. 135-150, jan./abr. 2010.

MORAES, R.; GALIAZZI, M. do C.; Análise textual discursiva. Ijuí: Editora Unijuí, 2007.

MORAES, R.; GALIAZZI, M. do C. Análise textual discursiva. 2. ed. Ijuí: Editora Unijuí, 2011. 
MORAES, R.; GALIAZZI, M. do C. Análise textual discursiva. 3. ed. Rev. e Ampl. Ijuí: Editora Unijuí, 2016.

LAWN, C.; KEANE, N. The Gadamer Dictionary. Londres: A\&C Black, 2011.

SOKOLOWSKI, R. Introdução à Fenomenologia. 4. ed. São Paulo: Edições Loyola, 2014.

SOUSA, R. S. de.; GALIAZZI, M. do C. Compreensões Acerca da Hermenêutica na Análise Textual Discursiva: Marcas Teórico-Metodológicas à Investigação. Contexto \& Educação, Ijuí, v. 31, n. 100, p. 33-55, abr. 2016.

SOUSA, R. S. de; GALIAZZI, M. do C. A Categoria na Análise Textual Discursiva: Sobre Método e Sistema em Direção à Abertura Interpretativa. Revista Pesquisa Qualitativa, São Paulo, v. 5, n. 9, p. 514-538, dez. 2017.

SOUSA, R. S. de; GALIAZZI, M. do C. O jogo da compreensão na análise textual discursiva em pesquisas na educação em ciências: revisitando quebra-cabeças e mosaicos. Ciência \& Educação, Bauru, v. 24, n. 3, p. 799-814, jul./set. 2018.

SOUSA, R. S. de; GALIAZZI, M. do C.; SCHMIDT, E. B. Interpretações fenomenológicas e hermenêuticas a partir da análise textual discursiva: a compreensão em pesquisas na educação em ciências. Revista Pesquisa Qualitativa, São Paulo, v. 4, n. 6, p. 311-333, dez. 2016.

Recebido em: 27 de outubro de 2020.

Aceito em: 18 de novembro de 2020. 